Educational Research \& Evaluation: An International Journal on Theory and Practice

Special Issue: Ethical Issues in Online Research

Editors: Nalita James and Hugh Busher

\title{
In pursuit of ethical research: Studying hybrid communities using online and face-to-face communications
}

*Hugh Busher, School of Education, University of Leicester

Nalita James, Vaughan Centre of Lifelong Learning, University of Leicester

${ }^{*}$ Corresponding Author

\section{Author Information:}

Nalita James, Vaughan Centre for Life Long Learning, 128 Regent Road, University of Leicester, University Road, Leicester, LE17RH, UK. T: 07821722432, E: nri7@le.ac.uk Hugh Busher, School of Education, University of Leicester, 21 University Road, Leicester, LE1 7RF, UK. T: +441162623664; E: hugh.busher@le.ac.uk

\section{Authors' brief biographies:}

Hugh Busher holds a PhD in the micro-politics of schools and supervises Masters and Doctoral students in the School of Education, University of Leicester. His research interests include critical perspectives on people, power and culture in education-based communities, representations of students' and teachers' voices, and hybrid learning communities.

\section{Nalita James}

Nalita James is senior lecturer in the Vaughan Centre for Lifelong Learning at the University of Leicester. Her research interests lie in the sociology of education and include: higher education; transitions from school to university and from education to work; changing patterns of education, work and identity; lifelong learning; and education policy. 


\title{
In pursuit of ethical research: Studying hybrid communities using online and face-to- face communications
}

Hugh Busher, School of Education, University of Leicester

Nalita James, Vaughan Centre of Lifelong Learning, University of Leicester

\begin{abstract}
Hybrid communities using online and face-to-face communications to construct their practices are increasingly part of everyday life amongst people who have easy access to the internet. Researching these communities raises a number of challenges for researchers in the pursuit of ethical research. The paper begins by exploring what is understood by hybrid communities and how their practices might be researched using hybrid methods to investigate the experiences of participants in them. The discussion then considers what might be an ethical framework for researching activity in these entities, giving examples from several projects that have tried carefully to embed this framework in their practices. In exploring these studies, the paper highlights the ethical possibilities and challenges that online and offline spaces offer for researchers in the conduct of their qualitative educational research.
\end{abstract}

Keywords: power, identity, relationships, space/ place, Access students 


\section{'To begin at the beginning'1}

The "embeddedness" of the internet in many people's everyday lives reflects the complexities of those lives and the hybrid nature of their experiences of "real life". Through their face-to-face and online communications people continuously re-interpret their identities and relationships and test these out with other people. Internet users' everyday lives are jointly constructed and interpreted out of a constant and complex interplay between physical and virtual worlds (Harrichan \& Bhopal, 2013) to make meanings in and of their lives in particular situations in time and space. It is a common misconception of the Internet that people's communications through it are somehow radically separate from their everyday life (Leander \& McKim, 2003, p.211). Actually people's online and offline worlds are deeply entangled in terms of space, time, place and embodiment. "Cyberspaces coexist with geographic spaces providing a new layer of virtual sites" (Kitchin, 1998, p. 403). So people, "make meaning of their experiences across online and offline spaces, producing identities without an exaggerated separation between these spaces" (Leander \& McKim, 2003, p.219).

As well as the internet, a host of social media platforms such as Twitter, Facebook and other blogging and visual social networking sites provide spaces in which people can interact bringing the here and there of their lives close together (Zhao, 2006). These, along with face-to-face and telephonic communications help people to construct hybrid communities. The term "hybrid can have at least three meanings - in terms of biology, ethnicity and culture. In its etymology it meant the offspring of a tame sow and a wild boar, an hybrida" (Easthorpe, 1998, p.145). Hybridity is a complex dynamic "communicative practice constitutive of, and constituted by, socio-political and economic arrangements" (Kraidy, 2002, p.318). The focus on hybrid cultures in this paper draws in part on the work of Bhabha (1994) to understand the meanings people construct through the relationships and communications they develop with others. These are interconnected with the development of new or emergent communities, cultures and personal identities constructed by their members. They provide researchers with a range of opportunities for investigating people's 
social lives but also present them with interesting ethical and practical challenges in collecting, interpreting and presenting data.

While Bhabha (1994) explored notions of hybridity through literature about people's physical, social and emotional experiences of transitions and transformations/ translations when migrating from one country to another, the same ideas can also be used metaphorically for people moving from one status or condition to another. In the case of our research (Busher, James, Piela \& Palmer, 2014; Piela, Busher, James, \& Palmer, 2013) this focused on the transitions and transformations of non-traditional students on the Access to Higher Education (AHE) Diploma qualification. This qualification is available In England and Wales to those who have been, "excluded, delayed or otherwise deterred by a need to qualify for [university] entry in more conventional ways" (Parry, 1996, p.11). For these students 'migration' was less between countries or states than between social situations, from that of often working in poorly paid unskilled jobs to becoming AHE students in order to move on to university to gain qualifications leading to more satisfying and better paid jobs, all the while trying to support their families in whatever accommodation they could find.

In moving or "relocating" from one state or status to another, people enter new spaces which are sometimes called "third spaces" (Bhabha, 1994) or marginal/ liminal places/ spaces. This usually also involves meeting with unfamiliar people in unfamiliar institutional spaces with whom they have to negotiate in unfamiliar socio-political contexts. When moving in to new spaces, understanding who are the "others", the notion of alterity (Amoamo, 2011) and who are the 'same' (Youdell, 2012) is important for helping people to recognise with whom they have to interact dynamically to assert their agency. In schools and colleges, the institutional spaces are constructed largely by teachers and senior staff to reflect dominant socio-political discourses about students of different ages, social backgrounds, genders, ethnicities and religions (Chandra, 2012). These tend to produce students as socially constructed stereotypes rather than as individual people with individual identities and agency. 
People are not passive in unfamiliar situations but try to assert some agency to achieve their own preferences and agenda (Moran, 2013). Agentic strategies include mimicry of dominant discourses (Bhabha, 1994); actions ranging from resistance to cooperation with dominant discourses and powerful people (Wolcott, 1977); recognition of who are significant others in particular circumstances (Youdell, 2012); analysis of what are the power differences between people in particular social structures and policy contexts and how power flows and decisions are made (Foucault, 1986) to construct particular institutional cultures which help to construct power (Giddens, 1984). How people make use of the physical, online and organisational spaces of an institution, whether or not they are formally allocated those, are part of the discourses about how they are constrained but try to assert their agency. Changing uses and demarcations of space through time reflect the changing relationships of people to each other and to the institution in which they are located (Paechter, 2004).

People entering new spaces, such as new students entering classrooms or colleges, often feel disoriented/ disempowered because they are unfamiliar with the culture, social structures and flows of power in them (Pierce, 2007). This destabilises people's sense of identity and how they perform that identity until they become familiar with who are the 'others' and how they help to construct social and physical spaces and flows of power in those situations as Paechter (2007) found when investigating how boys and girls constructed gendered identities in secondary schools. However, as people's identities are not fixed but shifting (Giddens, 1991), in different spaces people try to negotiate their presentations of themselves and their agenda in different but none the less coherent ways, shaping their presented identities to the dominant discourses around them (Benjamin, 2002). People's choice of how to position themselves comes through their internal conversations about who they are and how they relate to discourses and changing circumstances around them (Archer, 2003). Through this process people moving to new spaces begin to construct new cultures, called small cultures by Holliday (1999), which incorporate elements of local dominant discourses with their own values and past experiences (Busher, 2005). 
Within educational institutions, cultural (re)production takes place through people's interactions with policy discourses, institutional power structures and cultures and the people who project these, and the curricula structures and processes that privilege some aspects of knowledge and some ways of learning (Foucault, 2003). These discourses define what are legitimate subject knowledge and teaching practices and 'help decide what resources are legitimized or delegitimized in particular settings' (Gonsalves, Seiler \& Salter, 2011, p.394). Teachers/ tutors use these discourses to identify students as subordinates/ subalterns (Spivak, 1985) who are constrained by organisational structures and social practices to act in certain ways that reflect national and local discourses (Gonsalves et al., 2011). Metaphorically, the situation for students in educational institutions is similar to the subordination of native people by colonial regimes (Bhabha, 1994; Spivak, 1985), since students are portrayed as belonging to a caste whose attributes permanently exclude them from joining the ranks of the dominant group in an educational institution, the teacher/ tutors and senior managers. These two groups are usually made up of people with particular formal institutional status and qualifications. According to the dominant discourses of educational institutions, the teacher is always the ruler, at least formally. These essentialising discourses, "prompt a re-examination of what is invested in positioning the self

and other [in] dialectically essentialised cultures" (Amoamo, 2011, p.1255). In our research, some AHE students resented being identified as subordinates, in part because they were mature adults who were struggling to maintain families, homes and jobs, as well as undertaking a course of study. They perceived themselves as partners in constructing the learning processes of the hybrid communities which the AHE courses became (Busher, et al., 2014).

\section{Hybrid face-to-face/ online communities}

Hybrid communities are not post-modern bricolages, with various shreds and patches mechanically stuck together through which a person moves from one aspect to another, 
choosing whatever takes her or his fancy. Rather, emerging hybrid communities are suffused with power which people assert in a variety of ways (Giddens, 1984; Busher, 2006). The different aspects of the communities interact with each other dynamically through the agency of the people inhabiting them in particular policy contexts, creating a new transformed whole to which the original bits and pieces contribute. These include people's different histories (Chandra, 2012) and changing perspectives of themselves and their new situations. These hybrid communities are not necessarily "cohesive and homogenous social objects" (Handley, Sturdy, Fincham \& Clark, 2006, p.642). The dispersions and constructions of space in these communities, as well as access to them, are conduits and sites of power (Foucault 1977) which privilege some people's engagement because of the micro-political processes of the community (Jurasaite-Harbison, 2009). The transferable skills which people bring to them (Gonsalves et al., 2011) such as greater familiarity with digital technology (Cook-Sather, 2006) make some participants more powerful than others, at least initially during the construction of a community.

Educational institutions increasingly use online technologies to make learning resources available and encourage students to develop their capacities as independent learners (James \& Busher, 2013). They make use of a range of multimodal technologies to develop formal or informal learning, sometimes called blended learning (Littlejohn \& Pegler, 2006) creating a complex relationship between online and offline relationships (Coffey, Renold, Dicks, Soyinka \& Mason, 2006). Online communications can be used to enhance the physical learning spaces of a course and extend, "social interactions, storage and dissemination of knowledge" (Gaved \& Mulholland, 2005, p.1). For students, an important element of development on many courses is developing their digital technology skills and learning to make use of the internet in their everyday lives (Beneito-Montagut, 2011). On the AHE courses all the colleges used VLEs (Virtual learning environments) to support students learning and encouraged them to use email and telephonic communications with their tutors (Busher et al., 2014). 
People in these hybrid communities make use of online/ offline communications to construct new small cultures (Holliday, 1999) and shift identities. Although intensely local to the participants, hybrid communities incorporate global influences of the "others" time and space, too, including national and local educational discourses. Age, gender, social status and levels of cognitive knowledge are likely to be important factors that affect participation in hybrid communities although teachers' interactions with students tend to mediate the impact of age (Shea \& Bidjerano, 2013). The impact on AHE students of the development of these hybrid communities was to facilitate their learning and begin to transform their identities as learners from ones of educational failure as a consequence of their prior educational experiences, to ones of being capable independent learners (Piela et al., 2013).

Informal learning by students takes place online as well as offline (Leander \& McKim, 2003), individually and in collaboration with others both peers/ colleagues and older or younger people. In our study, some AHE students developed study groups and online communities on Facebook to help them with / complement their formal learning on their courses whether face-to-face or online (Busher et al., 2014). It allowed them to shift their uses of time for study to fit in with the rest of their lives. AHE students were mature adults who often had to support families and homes and maintain jobs to pay for these as well as attend their AHE courses. Their courses were temporary refuges lasting less than a year, sites where they interacted with each other, with tutors and with various socio-economic discourses and institutional practices to achieve their purposes. AHE students were vehemently committed to achieving the passes they need in their various assignments in order to enter higher education (HE) but recognised the difficulties of juggling this purpose with the other aspects of their lives (Busher et al., 2014).

\section{Approaches to researching hybrid communities}

Hybridity has considerable implications for the ethics of research, the relationships researchers construct with participants and the construction of trustworthy or credible 
research. In this perspective virtual or online sites involve social interaction (Hine, 2000) in which researchers need to become immersed to gain "access to the thoughts and experiences of those being studied" (Browne, 2003, p.249). The activities on the online sites complement face-to-face social interactions especially in hybrid communities. However, researching hybrid online / offline communities can heighten the risks for research participants who may be potentially more visible and more at risk from asymmetrical power relationships with researchers.

Online data collection can take two main forms: conducting "traditional" methods online and using "naturally occurring" (Madge \& O'Connor, 2005) online data. Traditional methods of collecting quantitative and qualitative data can be converted to online use. Sumuer, Ester \& Yildirim (2014) used surveys, interviews and documentary data on Facebook to investigate teachers' use of social media in Turkey. Constructions of meanings for observations of people's online activities can be created by "tracing the flows of objects, texts, and bodies, analysing the construction of boundaries within and around texts" (Leander \& McKim, 2003, p. 211). Fields and Kafai (2009) followed child gamers in and out of school as they interacted with each other and members of the virtual world at large using videos, tracking data, field notes and interviews. Online discussions potentially provide anonymity for participants, although not knowing to whom they are talking may discourage some people from choosing to participate. On the other had anonymity can encourage a more open and honest discussion (James \& Busher, 2009).

Researchers can gain access to many online or hybrid online and face-to-face communities by using a range of traditional research methods adapted to the online world. This allows researchers to investigate the meanings constructed by people using a wide range of online spaces such as newsgroups (Madge \& O'Connor, 2005) blogs (Hookway, 2008) social networking sites, chat rooms - "where participants often become strongly involved and ... manage and enhance their images on particular topics" (Shoham, 2004, p. 855) -, digital videos, such as YouTube, electronic face-to-face communication by VolP (Voice over Internet Protocols, e.g. Skype) and text-based email, whether synchronous or 
asynchronous (James \& Busher, 2013). Further, using online spaces as an adjunct to faceto-face data collection in research projects can have practical advantages for researchers, avoiding the need for physical venues and transport costs to research sites. Online discussions make it possible for researchers to explore the views of a wider range of participants and international and cross-cultural perspectives more easily (Busher \& James, 2012). Ethical participation on websites, chatrooms and social media pages allow researchers not only to, "textually construct her participants but also herself and her social world" (Leander \& McKim, 2003, p.214).

The online environment is also a rich source of 'naturally occurring' data from online and hybrid communities. Over recent years researchers have been able to collate vast quantities of information from websites through data mining (Hawi, 2013). Social media sites as well as being sources of information can also be used as means of finding participants for studies (Marsh \& Bishop, 2014). Tools for carrying out research with people on online sites, such as social media, blogs or newsgroups can be adapted from face-to-face research methods, be physical or digital in form and might include written or copied notes, screen grabs, photographs, diagrams or videos. Collecting multimodal material signals the central part played by visual, gestural and kinaesthetic modes in interpersonal communications, alongside language, in the development and expression of meaning (Jewitt, 2009; Kress, 2010).

Taking this broad approach to making sense of participants' engagements in hybrid online/face-to-face social situations challenges orthodox notions of a research site or field as a physical place / space for performing identity construction and interpersonal relationships. Instead it offers the more flexible notion of site as a space or field of social relationships (Olwig \& Hastrup, 1997) that is located in social and policy contexts and inhabited by people interconnected by communications whether these are face-to-face or online. It emphasises how researchers need to actively socially engage and interact with their participants in online as well as face-to-face spaces in order to write the story of their situated context (James \& Busher, 2013). 
In our own research to investigate AHE students' views of their transitions and transformations as learners during their courses we combined two surveys of over 500 students in seven course providing institutions in England with student focus groups, document collection, observation of some student Facebook sites and AHE tutors' individual interviews (Busher et al., 2014). The student learning communities that developed on these courses in face-to-face formal and informal learning spaces were inextricably linked with the students' online spaces, including college-based VLEs and private Facebook sites. The last were used both for social networking and to support their studies. For the students, the AHE courses were hybrid communities that offered the opportunity to negotiate the transformations of their identities and values through forming new online/offline relationships with others who were in similar situations to themselves.

\section{In pursuit of ethical research}

Being involved in research into multi-sited hybrid communities raises questions about how to ethically engage with the participants when collecting, analysing and writing up the data. In social research, ethics refers to the moral deliberation, choice and accountability on the part of researchers throughout the research process (James \& Busher, 2007). As such research ethics goes beyond the use of university ethics committees or institutional review boards and the paraphernalia of ethical approval protocols with which researchers have to engage: guidelines, ethical approval request forms, and participant consent forms. Wellestablished ethical codes of conduct such as the Economic and Social Research Council (ESRC, 2011) or the British Educational Research Association (BERA, 2011) give valuable guidance to researchers. However, researchers can never avoid the necessity of engaging actively and reflexively with the potential ethical dilemmas embedded in their research throughout the life of a research project (Hammersley, 2006). This involves at times, not just a willingness by researchers to question who they are but who others are, too, and to question what seems obvious (Culbertson, 2013). This is even more critical when research 
is being conducted in technology-mediated social spaces. With the emergence of new digital technologies and social media, 'moral deliberation' about who the participants are, what is private/public and how data is stored, can become confused or even lost (Henderson, Johns \& Auld, 2013).

Carrying out research in hybrid online/face-to-face spaces, where individuals participate in communities that are simultaneously online and face-to-face, requires an ethical practice that is closely linked to constructing collaborative cultures in which the researchers act as hosts (Derrida, 2000) for their projects, inducting new participants into them (James and Busher, 2013). This involves clarifying the rules of engagement with participants so that the research is carried out in a respectful manner and keeps participants safe from harm, preserves privacy, builds trust with participants and ensures trustworthy outcomes from research (Lee, 2006). This important deontological stance avoids exposing participants to potential harm. However, researchers can only do this with "the direct and indirect contributions of colleagues, collaborators and others" (ESRC, 2011, p. 23). When research is located online or in hybrid spaces this can be achieved by viewing research ethics as a dialogic process, in which ethics informs the development of a study for a particular purpose and is iterative in the sense that it is developed and reworked during the study and focuses on the relationship between the researcher and participants (Henderson, Johns \& Auld, 2013).

People's different perspectives on social situations in hybrid spaces, whether expressed in text or visually formed "ethical spaces" are activated through the interactions of researchers, participants and readers (Lovheim, 2011). Hybrid spaces can become spaces for creative self-expression and reflection or for voicing concerns and views on issues in people's lives as we found in our study of AHE students (Busher et al., 2014) which is discussed below. However, the representation of people in physical or online spaces is always a matter of considerable concern ethically because of the risks of causing harm to research participants. The problem is exacerbated because representation of people in one space often has a dynamic interrelationship with that in others. Images, too, in representing 
aspects of social structures in their particular contexts can make the institutional spaces of research visible when writing up studies, threatening to undermine the privacy of participants.

The use of digital technology heightens the problem because of the ease with which representations of participants can be made easily available in online/offline spaces. Some researchers have suggested that internet spaces are neither public nor private and that publicly accessible online data can be used in research without participants' consent (Paccagnella, 1997). However, other researchers prefer to acknowledge the autonomy of research participants (Wiles, Prosser, Bagnoli , Clark, Davies, 2008) and request participants' permission to use their images or texts in research whether or not they are publically accessible on the internet.

Research on social media sites such as Facebook and Twitter raise various ethical issues as they are hybrid public spaces - what people present online affects how they are perceived in face-to-face interactions and their choices of how they present themselves online may be affected by values that are established in face-to-face communications with communities that are, for them, significant others. In some cases, even though participants may be only intending to communicate with each other online, viewing the online space as private, in effect they are communicating in a public space to which other people can gain access (James \& Busher, 2013). Consequently researchers have to ensure that participants and their families and communities are protected from harm in both online and offline spaces, including harm to their reputations. As with research participants on internet websites (Madge \& O'Connor, 2005) researchers on social media sites need to ensure that all the participants in a particular community with whom they want to carry out research give their voluntary informed consent to take part. This also avoids researchers unintentionally and unethically lurking on community sites (James \& Busher, 2009). If some members of a community choose to withhold their permission their data has to be removed from the research record of that community. 


\section{Ethical practice in hybrid educational communities}

It is instructive to look at how these ethical frameworks for research have been played out in studies of hybrid communities by different educational researchers. The examples shown below have similarities and differences: the first three come from intentional communities (Mangham, 2012) set up during courses of study or research in HE. The last two come from research focused on open or publically accessible online sites.

The first example comes from one institution in one country making use of action research to help trainee teachers develop their thinking as putative teachers. A teacher educator used blogs to encourage student teachers to reflect on their developing practice as pre-service teachers in understanding geographical concepts and ideas and approaches for lessons (Wood, 2012). Through using liminal spaces on the internet to reflect on practice on physical sites - student teachers' placement schools for teaching practice - student teachers made important transitions in the development of their repertoire of practices and identities as trainee and future teachers. However, the power imbalances between the teacher educator and the students raised ethical questions about the quality of consent given by the students and the safeguarding of their privacy. The latter was addressed by the students writing blogs on secure sites where non-participants in the study could not enter and the study being written up anonymously. An important feature of the study was the tutor and students building values of trust and collaboration in their learning community.

The second example is of international collaboration in teacher education to develop thinking about teaching a particular area of knowledge. In this case, researchers used a wiki to enable pre-service teachers to share their developing understandings of teaching poetry in Secondary schools, their evaluations of their experiences of teaching poetry during teacher-training placements and their views on using wikis for teaching purposes (Hughes \& Dymoke, 2011). In addition the wiki allowed participants to compare their perspectives across departments of education for student teachers in England and Canada. In each country student teachers worked with each other and their tutors face-to-face, making the 
tutors as researchers participant observers of both sites online and offline. However, the power differentials between teacher educators and pre-service teachers, and the differing roles of the tutors as both tutors and researchers highlighted the complex relationship between researchers and participants online and offline. Although the wiki that was used was not in a public online space, avoiding the potential for invading their privacy which the student teachers might have faced through their posts, the extent to which participants might be said to have given voluntary informed consent to participate is problematic, even if it is what student teachers and tutors claimed happened. Writing up the study was similarly problematic as any revelation of the institutions involved in the study risked revealing at least the group of student teachers who took part, if not the individuals themselves.

A third example of the ethical complexities of research in hybrid communities comes from Kidd (2011) who constructed an artificial community of bloggers for the purposes of research. Like other hybrid communities, it functioned in the liminal spaces online between the participants and the researcher, allowing participants to be both present and absent simultaneously. Newly qualified teachers in their first year of full-time teaching were asked to develop narratives on blogs about their experiences in schools. This was so the researcher could assess the impact of teacher education provision and trainee teachers' readiness for changing professional identities and roles in the first sixth months of employment. The information from these blogs was then used to inform the development of a pre-service teachers' training course. Although this process seems ethically unproblematic - discussion taking place in a closed online space, the blog - it raises some awkward questions for participants. By making public their early experiences as new teachers in particular institutions, which other bloggers might have known, and relating these to their previous teacher training, the blog had the potential to damage the reputations of both novice teachers and the institutions in which they worked. To avoid this, the researcher and the other participants had to be very careful not to allow what they found out through the blog to influence what they said outside that environment. 
The remaining two examples are taken from studies involving hybrid communities using publically accessible online sites the material on which interacts with people's face-toface lives. The online sites are part of people's hybrid activities through which they build connections and communities online and face-to-face. The first example is from our study of AHE students (Busher et al., 2014; Piela et al., 2013) where students used email and telephonic communications with tutors and in six of the seven providing institutions had set up social media sites and informal face-to-face study groups to complement their work in the formal classes of their courses. In addition students on four courses used institutional VLEs to develop independent learning. These AHE courses were hybrid communities which only met for formal lessons on two or three days each week during term time because many of the AHE students also had to have jobs to sustain their families and pay their course fees. Problematically, we only discovered that AHE students were using online communications to support their learning during the first round of face-to-face interviews in Autumn 2012 (Busher et al., 2014; Piela et al., 2013). Although we had gained informed consent from participants before carrying out the first interviews this permission only extended to face-toface discussions. Further, because the students in the interviews were only a sample of those on each AHE course, there were many students participating in the AHE social media sites in each institution who had not given their consent to talk with us. If we were to investigate AHE students' interactions on their social media sites we had to gain permission from all the students who were members of those sites.

This was not quite as straight forward as it might seem. In two of the colleges the moderators of the AHE students' Facebook pages were members of the focus groups we were interviewing. In both cases they offered to allow us access to the sites. However we did not know the gatekeepers of the social media sites in the other four colleges. Further the kind offer by the gatekeepers we did know did not necessarily give us the informed consent of all the members of their sites (ESRC, 2011). As we wanted to treat all the social media sites equally we decided to post to each student Facebook site and ask members to give their informed consent to take part in our study. This, in turn, raised an issue about how we 
posted to these social media sites since if we used our private social media addresses it would make us and our networks visible to the students. So we now had a double dilemma of both getting students' informed consent and protecting the private lives of the researchers (ESRC, 2011).

We tackled the protection of researchers' privacy by creating a Facebook identity for the project, linked to its website and email address. This became the entity which posted to the AHE students' Facebook pages, the addresses of which we obtained from our focus group participants, and avoided the researchers being personally visible on the students' Facebook sites. The project was a known entity amongst all the AHE students in the institutions through the questionnaires we had sent out and through our focus group interviews with some of them.

To address the problem of gaining informed consent from all AHE students on each Facebook site, we decided to explain in a post to each site who we were and why we wanted access to their sites and that we wanted their permission to do so. We thought it would be unethical to lurk on the students' Facebook sites and download posts from them without students' explicit permission. To avoid disturbing or distorting the conversational flows of the sites we decided not to join in with any of the conversations, even if we had the knowledge to do so and were explicitly invited by participants. We explained this in our post. To avoid students worrying about what might happen to their posts if we captured them - a hugely time consuming process - we guaranteed that we would render them anonymous before using them in the study. To cope with any participant on an AHE Facebook site who did not want to take part in the project, we decided, as we explained in our post, that we would cut out their material from our record of the Facebook conversations. It was a considerable relief when, several weeks after our post none of the students participating in the Facebook sites had raised any objections to our research activities.

The second example is from a study into Muslim women's self-representation on the internet. This constituted a hybrid public community where online and offline communication intermingled and religious beliefs around appropriate behaviour confronted Western 
dominated values of individuality (Piela, 2010). As human form is absent from public settings in Islam, traditionally, "research on photos produced and published by Muslim women on the internet juxtaposes Western concepts of identity and self-representation with Islamic understandings of modesty" (Piela, 2010, p. 87). The Muslim women who produced these self-portraits were both their authors and their subjects, "authors-subjects" (Piela, 2010, p. 93). By analysing and interpreting these photos in the particular contexts of the internet, researchers can gain some insight into how Muslim women see themselves and the world that surrounds them, "thus reversing the power dynamic of the Orientalist gaze that asserts itself through framing and contextualizing the object" (Piela, 2010, p. 91).

To address the ethical issues that this research raised, although the photos were freely available on the internet and not on password protected sites, Piela (2010) preferred to acknowledge her research participants' ownership of their images (Wiles et al., 2008) and requested participants' permission to use their images in her research. She thought that using the images for purposes different from the authors' original intention (research rather than self-representation) made it necessary, ethically, for her to gain the permission of her participants to use their photographs. She also recognised that she had to safeguard the privacy of her participants, whom she contacted through a photo-sharing website messaging system, so stored the data securely and changed the names of the participants, removing any biographical details linked to the images that might allow their identification (Piela, 2010, p. 92).

\section{Conclusion}

Social relationships are the sites through which people develop their identities, social groups and particular cultures in the contexts of broader social and policy discourses. People use online, visual and textual media interactively with face-to-face communications to develop and sustain social relationships whether for work or pleasure (Littlejohn \& Pegler, 2006; Coffey et al., 2006). Although, hybrid online/face-to-face communities are commonplace 
people engage with them to differing extents. Some people are more adept at using both worlds and this may be related in part to age, gender, social class and technical knowledge, as well as to people's values and ethics. In learning environments, teachers can mediate the impact of these social factors to some extent (Shea \& Bidjerano, 2013).

If researchers wish to study the social processes of people in groups where their participants use a variety of face-to-face and online media to communicate with each other they need to replace narrow views of place as the physical site for people's actions with broader views of space as the multiple locations which people inhabit in hybrid online/faceto-face worlds (Olwig \& Hastrup, 1997). To investigate these hybrid worlds researchers need to understand people's online communications, their face-to-face engagement and the interactions of both (James \& Busher, 2013). To do so however, requires researchers to think carefully about how they apply understandings of ethical practice to complex social situations.

To follow people through the interstices of their online-offline worlds, researchers need to become sophisticated in using multimodal approaches whether to investigate how individuals think, feel and act or how groups of people interact, create cultures and use/ experience power in pursuit of particular agenda (Browne, 2003), as Fields and Kafai (2009) did in their study. Such studies raise ethical challenges to researchers to ensure that participants are kept safe from harm so that trustworthy knowledge is constructed that is of benefit to wider societies (Sikes, 2006). Careful reflection on ethical processes for online and face-to-face data collection and curation at all stages of a research project and the explanation of these to putative participants in a project help to build a culture of trust in it (Lee, 2006; Busher \& James, 2012). This empowers participants and facilitates their willingness to engage meaningfully with a project in constructing carefully grounded responses to the research questions as well as building truthful knowledge on which future research can safely build.

Researchers can avoid using multimodal methods of data collection and analysis and the ethical conundrums they pose by choosing to investigate just the face-to-face or online 
aspects of individual people's lives or people's interactions in communities or groups.

However, in doing so researchers have to recognise that they are probably capturing only a portion of participants' stories. Admittedly in some instances / locations / research objectives it might be appropriate to only focus on the online or face-to-face world of their participants rather than on the excitingly hybrid but in making that choice researchers will have to be more cautious than usual with their claims to knowledge.

\section{Notes}

1. 'To begin at the beginning' Thomas, D. (1954) Under Milkwood. London: BBC Radio Collection

\section{References}

Amoamo, M. (2011).Tourism and hybridity: Revisiting Bhabha's third space. Annals of Tourism Research, 38(4), 1254-1273. DOI:10.1016/j.annals.2011.04.002

Archer, M. (2003). Structure, agency and the internal conversation. Cambridge: Cambridge University Press.

Beneito-Montagut, R. (2011). Ethnography goes online: Towards a user-centred methodology to research interpersonal communication on the internet. Qualitative Research, 11(6), 716-735. DOI: 10.1177/1468794111413368

Benjamin, S. (2002). The micro-politics of inclusive education. Buckingham: Open University Press.

Bhabha, H. (1994) The location of culture. London: Routledge

British Educational Research Association (BERA) (2011). Revised ethical guidelines for educational research. London: BERA. 
Browne, E. (2003). Conversations in cyberspace: A study of online learning. Open Learning: The Journal of Open and Distance Learning, 18(3), 245-259.

DOI:10.1080/0268051032000131017

Busher, H. (2005). The project of the other: Developing inclusive learning communities in schools. Oxford Review of Education, 31(4), 459-477.

DOI:10.1080/03054980500222221

Busher, H. (2006). Understanding educational leadership: People, power and culture Maidenhead: Open University Press/McGraw-Hill.

Busher, H. \& James, N. (2012). Ethics of research in education. In A. Briggs, M. Coleman \& M. Morrison (Eds.), Research methods in educational leadership and management (3rd ed, pp.90-104). London: Sage.

Busher, H., James, N., Piela, A. \& Palmer, A-M. (2014). Transforming marginalised adult learners' views themselves: Access courses in England. British Journal of Sociology of Education, 35(5), 800-817. DOI:10.1080/01425692.2014.919842

Chandra, P. (2012). Marxism, Homi Bhabha and the omissions of postcolonial theory: Critique. Journal of Socialist Theory, 40(2), 199-214.

DOI:10.1080/00111619.2012.664727

Coffey, A., Renold, E., Dicks, B., Soyinka, B., \& Mason. B. (2006). Hypermedia ethnography in educational settings: Possibilities and challenges. Ethnography and Education, 1(1), 15-30. DOI:10.1080/17457820500512721

Cook-Sather, A. (2006). Newly betwixt and between: Revising liminality in the context of a teacher preparation programme. Anthropology and Education Quarterly, 37(2), 110127. DOI: 10.1525/aeq.2006.37.2.110

Culbertson, C. (2013). The ethics of relationality: Judith Butler and social critique. Continental Philosophical Review, 46(3), 449-463.

DOI: 10.1007/s11007-013-9271-z

Derrida, J. (2000). Of hospitality. Stanford Ca: Stanford University Press. 
Easthorpe, A. (1998). Homi Bhabha, hybridity and identity, or Derrida versus Lacan. Hungarian Journal of English and American Studies, 4(1/2), 145-151.

Economic and Social Research Council (ESRC) (2011). Research Ethics Framework. Swindon: ESRC.

Fields, D. A. \& Kafai. Y. B. (2009). A connective ethnography of peer knowledge sharing and diffusion in a tween virtual world. International Journal of Computer-Supported Collaborative Learning, 4(1), 47-68. DOI: 10.1007/s11412-008-9057-1

Foucault, M. (1977). Discipline and Punishment: The Birth of the Prison (A. Sheridan, Trans.). Harmondsworth: Penguin.

Foucault, M. (1986). Disciplinary Power and Subjection. In Lukes, S. (Ed.), Power (pp.12-23) Oxford: Blackwell.

Foucault, M. (2003). Birth of the Clinic (Tavistock publications 1973, Trans.). Abingdon: Routledge.

Gaved, M. \& Mulholland, P. (2005). Grassroots initiated networked communities: A study of hybrid physical/ virtual communities. Proceedings of the 38th Hawaii International Conference on System Sciences (HICSS-38), Hawaii, USA, 2005. Page(s): 191c DOI:10.1109/HICSS.2005.288

Giddens, A. (1991). Modernity and self-identity: Self and society in the late modern age. Cambridge: Polity Press.

Giddens, A. (1984). The constitution of society. Cambridge: Polity Press.

Gonsalves, A., Seiler, G. \& Salter, D.E. (2011). Rethinking resources and hybridity. Cultural Studies of Science Education, 6(2), 389-399. DOI 10.1007/s11422-010-9275-5. Hammersley, M. (2006). Ethnography: Problems and prospects. Ethnography and Education, 1(1), 314. DOI:10.1080/17457820500512697

Handley, K., Sturdy, A., Fincham, R., \& Clark, T. (2006). Within and beyond communities of practice: Making sense of learning through participation, identity and practice. Journal of Management Studies, 43(3), 641-653.

DOI: $10.1111 / j .1467-6486.2006 .00605 . x$ 
Hawi, N. (2013). Knowledge mining from human interactions with the internet. Global Journal on Technology, 4, 486-492 [Available Online from: www.awer-center.org/pitcs]

Henderson, M., Johns, N.F., \& Auld, G. (2013). Silences of ethical practice; Dilemmas for researchers using social media, Educational Research and Evaluation: An International Journal on Theory and Practice, 19(6), 546-550.

DOI:10.1080/13803611.2013.805656

Harrichan, M. \& Bhopal, K. (2014). Using blogs in qualitative educational research: An exploration of method. International Journal of Research and Method in Education, 37(3), 324-343. DOI:10.1080/1743727X.2014.885009

Hine, C. (2000). Virtual ethnography. London: Sage.

Holliday, A. (1999). Small cultures. Applied Linguistics, 20(2), 237-264.

DOI:10.1093/applin/20.2.237

Hookway, N. (2008). "Entering the blogosphere": some strategies for using blogs in social research. Qualitative Research, 8(1), 91-113. DOI:10.1177/1468794107085298

Hughes, J. \& Dymoke, S. (2011). “Wiki-Ed poetry”: Transforming pre-service teachers' preconceptions about poetry and poetry teaching. Journal of Adolescent and Adult Literacy, 55(1), 46-56. DOI: 10.1598/JAAL.55.1.5

James, N. \& Busher, H. (2007). Ethical issues in online educational research: protecting privacy, establishing authenticity in email interviewing. International Journal of Research and Method in Education, 30(1), 101-113.

DOI:10.1080/17437270701207868

James, N. \& Busher, H. (2009). Online interviewing. London: Sage.

James, N. \& Busher, H. (2013). Researching hybrid learning communities in the digital age through educational ethnography. Ethnography and Education, 8(2), 194-209.

DOI:10.1080/17457823.2013.792509

Jewitt, C. (2009). Routledge handbook of multimodal analysis. Abingdon: Routledge. 
Jurasaite-Harbison, E. (2009). Teachers' workplace learning within informal contexts of school cultures in the United States and Lithuania. Journal of Workplace Learning, 21(4), 299-321. DOI:10.1108/13665620910954201

Kidd, W. (2011, May). Using online communities, wikis and blogs to capture the 'boundary crossing' of novice teachers: An action research enquiry on the margins of digital ethnography. Paper presented at the conference on Rethinking Educational Ethnography: Researching On-line Communities and Interactions Conference, University of Porto, Porto, Portugal.

Kitchin, R. M. (1998). Towards geographies of cyberspace. Progress in Human Geography, 22(3), 385-406. DOI:10.1191/030913298668331585

Kraidy, M.K. (2002). Hybridity in cultural globalization. Communication Theory, 12(3), 316339. DOI: 10.1111/j.1468-2885.2002.tb00272.x

Kress, G. (2010). Multimodality: A social semiotic approach to contemporary communication. Routledge: London.

Leander, K. M. \& McKim, K.K. (2003). Tracing the everyday 'sitings' of adolescents on the internet: A strategic adaptation of ethnography across online and offline spaces. Education Communication and Information, 3(2), 211- 240.

DOI:10.1080/14636310303140

Lee, H. (2006). Privacy, publicity and accountability of self-presentation in an online discussion group. Sociological Inquiry, 76(1), 1-22. DOI:10.1111/j.1475- 682X.2006.00142.x

Littlejohn, A. \& Pegler, C. (2006). Preparing for blended e-Learning: Understanding blended and online learning. London: Routledge.

Lovheim, M. (2011). Young women's blogs as ethical spaces. Information Communication and Society, 14(3), 338-354. DOI:10.1080/1369118X.2010.542822

Madge, C. \& O'Connor, H. (2005). Mothers in the making? Exploring liminality in cyber/space. Transactions of the Institute of British Geographers, 30(1), 83-97. DOI: 10.1111/j.1475-5661.2005.00153.x 
Mangham, C. W. (2012). A combined framework for investigating communities of practice and the function of the learning organisation: A case study of an industrial training unit in the United Arab Emirates (Unpublished doctoral thesis). University of Leicester, Leicester, UK.

Marsh, J. \& Bishop, J.C. (2014). Challenges in the use of social networking sites to trace potential research participants. International Journal of Research and Method in Education, 37(2), 113-124. DOI:10.1080/1743727X.2013.820642

Moran, D. (2013). Between outside and inside? Prison visiting rooms as liminal carceral spaces. Geo Journal, 78, 339-351. DOI: 10.1007/s10708-011-9442-6

Olwig, K.F. \& Hastrup, K. (1997). Introduction. In Olwig, K.F. \& Hastrup, K. (Eds.), Siting culture (pp.1-16). New York: Routledge.

Paccagnella, L. (1997). Getting the seats of your pants dirty: Strategies for ethnographic research on virtual communities. Journal of Computer-Mediated Communication, 3(1), $0 . \quad$ DOI: $10.1111 /$ j.1083-6101.1997.tb00065.x

Paechter, C. (2004). Space, identity and education. Pedagogy, Culture and Society, 12(3), 307-308. DOI:10.1080/14681360400200204

Paechter, C. (2007). Being boys, being girls: Learning masculinities and femininities. Abingdon: McGraw Hill.

Parry, G. (1996). Access education 1973-1994: From second chance to third wave. Journal of Access Studies, 11(1), 10-33.

Piela, A. (2010). Challenging stereotypes: Muslim women's photographic selfrepresentations on the Internet. Heidelberg Journal of Religion on the Internet, 4(1), 87-110. DOI: 10.11588/rel.2010.1.9386

Piela, A., Busher, H., James, N. \& Palmer, A-M., (2013) Agency and future life trajectories in accounts of access to higher education students in England. In B.Käpplinger, N. Lichte, E. Haberzeth \& C. Kulmus (Eds.)(2014), Changing Configurations of Adult Education in Transitional Times: Proceedings of the 7th European Research Conference (pp.165-179). Berlin: Humboldt-Universität. 
Pierce, K.A. (2007). Betwixt and between: Liminality in beginning teaching. The New Educator, 3(1), 31-49. DOI:10.1080/15476880601141615

Shea. P. \& Bidjerano . T. (2013) Understanding distinctions in learning in hybrid and online environments: An empirical investigation of the community of inquiry framework. Interactive Learning Environments, 21(4), 355-370.

DOI:10.1080/10494820.2011.584320

Shoham, A. (2004). Flow experiences and image making: An online chat-room ethnography. Psychology and Marketing, 21(10), 855-882. DOI: 10.1002/mar.20032

Sikes, P. (2006). On dodgy ground? Problematics and ethics in educational research. International Journal of Research and Method in Education, 29(1), 105-117. DOI:10.1080/01406720500537502

Spivak, G.C. (1985). The Rani of Sirmur: An essay in reading the archives. History and Theory, 24(3), 247-272.

Sumuer, E., Esfer, S. \& Yildirim, S. (2014). Teachers' facebook use: Their use habits, intensity, self-disclosure, privacy settings, and activities on facebook. Educational Studies, 40(5), 537-553. DOI:10.1080/03055698.2014.952713

Wiles, R., Prosser, J., Bagnoli, A., Clark, A., Davies, K., Holland, S., \& Reynold, E. (2008). Visual ethics: Ethical issues in visual research. ESRC National Centre for Research Methods Review Paper. Available at: http://eprints.ncrm.ac.uk/421/1/MethodsReviewPaperNCRM-011.pdf.

Wolcott, H. (1977). Teachers versus technocrats. Ann Arbor, Mi: Centre for Education Policy Making, University of Oregon.

Wood, P. (2012). Blogs as liminal space: Student teachers at the threshold. Technology, Pedagogy and Education, 21(1), 85-99. DOI:10.1080/1475939X.2012.659885

Youdell, D. (2012). Fabricating 'pacific islander': Pedagogies of expropriation, return and resistance and other lessons from a 'multicultural day'. Race Ethnicity and Education, 15(2), 141-155. DOI:10.1080/13613324.2011.569243 
Zhao, S. (2006). The internet and the transformation of the reality of everyday life: Toward a new analytic stance in sociology. Sociological Inquiry, 76(4), 458-474.

DOI: 10.1111/j.1475-682X.2006.00166.x 